Arkivoc

Free to Authors and Readers
A Platinum Open Access Journal for Organic Chemistry

Paper

DOAJ Seal

Arkivoc 2021, part viii, 324-330

\title{
Catalyst-free rapid conversion of arylboronic acids to phenols under green condition
}

\author{
Zhenhua Dong, * Hongguo Pan, and Mengmeng Liu
}

College of Chemistry and Chemical Engineering, Henan University of Technology, Lianhua Street 100, Zhengzhou 450001, China

Email: zhdong@haut.edu.cn

Received 06-29-2021

Accepted Manuscript 07-31-2021

Published on line $08-10-2021$

\section{Abstract}

A catalyst-free and solvent-free method for the oxidative hydroxylation of aryl boronic acids to corresponding phenols with hydrogen peroxide as the oxidizing agent was developed. The reactions could be performed under green condition at room temperature within very short reaction time. $99 \%$ yield of phenol could be achieved in only $1 \mathrm{~min}$. A series of different arenes substituted aryl boronic acids were further carried out in the hydroxylation reaction with excellent yield. It was worth nothing that the reaction could completed within $1 \mathrm{~min}$ in all cases in the presence of ethanol as co-solvent.

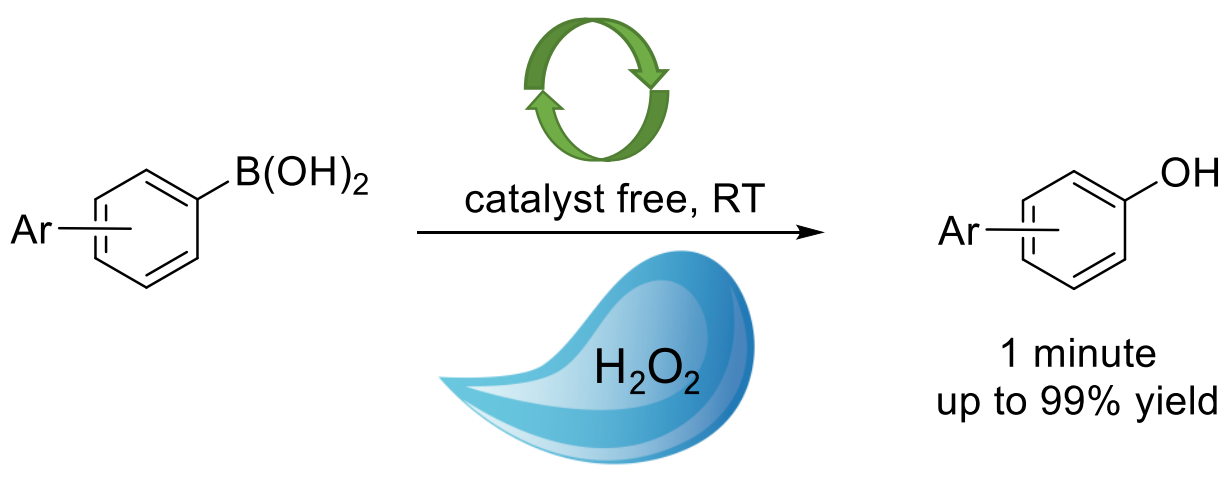

Keywords: Arylboronic acid; phenol; oxidation; catalyst-free; hydrogen peroxide 


\section{Introduction}

In the synthetic organic chemicals industry, especially in pharmaceuticals, agrochemicals and natural antioxidants, phenol and its derivatives are important building blocks and intermediates. ${ }^{1-4}$ Due to its important applications, a large number of methods have been developed for the synthesis of phenol and its derivatives, for example, the hydroxylation of aryl halides, non-oxidative electrophilic substitution, hydrolysis of diazonium salts, deprotection of phenol precursors, conversion of diazoarenes, addition of benzyne. ${ }^{5-7}$ However, these methods generally require harsh reaction conditions and exhibit limited substrate scope. Among existing reports, the direct oxidative hydroxylation of aryl boronic acids is one of the most important method which represents a convenient, regioselective and atom-economical process. ${ }^{8-13}$ The oxidative hydroxylation of aryl boronic acids have been widely reported and applied to afford phenols. A variety of oxidants have been applied, such as $\mathrm{O}_{2},{ }^{9,13} \mathrm{NaBO}_{3},{ }^{14} \mathrm{H}_{2} \mathrm{O}_{2},{ }^{8} \mathrm{Phl}(\mathrm{OAc})_{2},{ }^{15}$ etc... In order to facilitate the oxidation process, diverse conditions were also developed such as metal-catalyst, ${ }^{16}$ organo-catalyst, ${ }^{17}$ photocatalyst, ${ }^{13}$ catalyst-free or solvent-free ${ }^{1,}{ }^{4}$ etc... In view of sustainable and green chemistry, it was environmentally important to reduce the waste and pollution in the oxidative hydroxylation reactions by using green oxidant and solvent. Recently, several environmentally friendly methods have been reported to avoid the use of potentially toxic metal-catalysts. ${ }^{18-19}$ However, in most cases, longer reaction times and complex reaction systems were necessary. Herein, we report a catalyst-free condition for the transformation of aryl boronic acids to substituted phenols by using $\mathrm{H}_{2} \mathrm{O}_{2}$ as oxidant and solvent. $\mathrm{H}_{2} \mathrm{O}_{2}$ can be seen as a green reaction medium. In the previous reports, the oxidation employing $\mathrm{H}_{2} \mathrm{O}_{2}$ in the absence of catalyst is a very slow process..$^{12,20}$ However, the transformation of aryl boronic acids to phenols was very fast in this work. Excellent yields could be obtained in one minute for most substrates.

\section{Results and Discussion}

Initially, we wished to expand new catalytic applications for Ag nanoparticle which was synthesized in our lab previously. With this in mind, we used the hydroxylation of phenylboronic acid (1a) to the phenol (2a) as model reaction catalyzed by the Ag nanoparticle in order to optimize reaction conditions. The phenylboronic acid was transformed completely by using $20 \mathrm{mg} \mathrm{Ag}$ catalyst and $0.2 \mathrm{~mL} \mathrm{H} \mathrm{O}_{2}$ as oxidant in water (Entry 1 , Table 1). Next, we attempted to reduce the catalyst loading. Surprisingly, the oxidative hydroxylation of $1 \mathbf{a}$ also afforded the corresponding product $2 \mathrm{a}$ in almost quantitative yield using $0.4 \mathrm{~mL} \mathrm{H}_{2} \mathrm{O}_{2}$ (13 equiv. in this case) (Entry 2, Table 1). Compared with previous report, just $85 \%$ yield was achieved by using 3 equiv. $\mathrm{H}_{2} \mathrm{O}_{2}$ as oxidant in $10 \mathrm{~mL}$ water. ${ }^{12}$ It was obvious that the reaction speed could be increased along with the concentration increases of $\mathrm{H}_{2} \mathrm{O}_{2}$ (Entry 3, Table 1). Furthermore, the reaction occurred very rapidly (complete in $1 \mathrm{~min}$ ) with $99 \%$ yield when $1.6 \mathrm{~mL} \mathrm{H} \mathrm{O}_{2}$ was used as sole solvent and oxidant (Entry 4, Table 1). The pure product was easy to isolate without chromatography. 
Table 1. Oxidation of arylboronic acids ${ }^{a}$

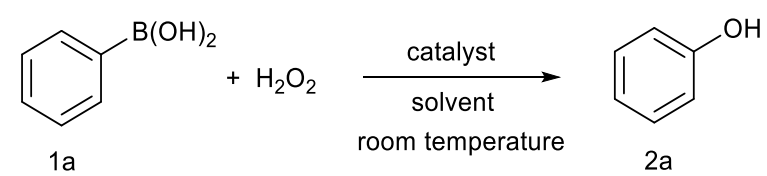

\begin{tabular}{llllll}
\hline Entry & Catalyst & Oxidant & Solvent & Time & Yield $^{\text {b }}$ \\
\hline 1 & Ag NPs & $0.4 \mathrm{~mL}$ & $1.2 \mathrm{~mL}$ & $5 \mathrm{~min}$ & $99 \%$ \\
2 & - & $0.4 \mathrm{~mL}$ & $1.2 \mathrm{~mL}$ & $5 \mathrm{~min}$ & $99 \%$ \\
3 & - & 0.8 & 0.8 & $3 \mathrm{~min}$ & $99 \%$ \\
4 & - & $1.6 \mathrm{~mL}$ & - & $1 \mathrm{~min}$ & $99 \%$ \\
\hline
\end{tabular}

a Reaction conditions: phenylboronic acid $(1 \mathrm{mmol}), \mathrm{H}_{2} \mathrm{O}_{2}$, water and catalyst at room temperature. $b$ Isolated yield.

A series of different substituted aryl boronic acids was subjected to the oxidative process under the optimized conditions, and the results are summarized in Table 2. Both the electron-withdrawing (2b-2h, table 2) and electron-rich (2i-2k, table 2 ) aryl boronic acids afforded the corresponding product in excellent yield in 3-12 minutes. The results demonstrates that the electronic nature of the substrates had no obvious influence on the yield. However, no products were detected when the arylboronic acids with para-substituents (2l-2r, table 2 ) and di-ortho substituents (2p, $\mathbf{2 q}$, table 2 ). The relatively low yields could be reasonably attributed to the substrates which was difficult to dissolve in $\mathrm{H}_{2} \mathrm{O}_{2}$ as sole solvent.

Table 2. Catalyst and solvent free hydroxylation of boronic acids ${ }^{a}$

$$
\underset{1}{\mathrm{Ar}-\mathrm{B}(\mathrm{OH})_{2}} \stackrel{1.6 \mathrm{~mL} \mathrm{H} \mathrm{O}_{2}}{\longrightarrow} \underset{2^{\mathrm{b}}}{\mathrm{Ar}-\mathrm{OH}}
$$

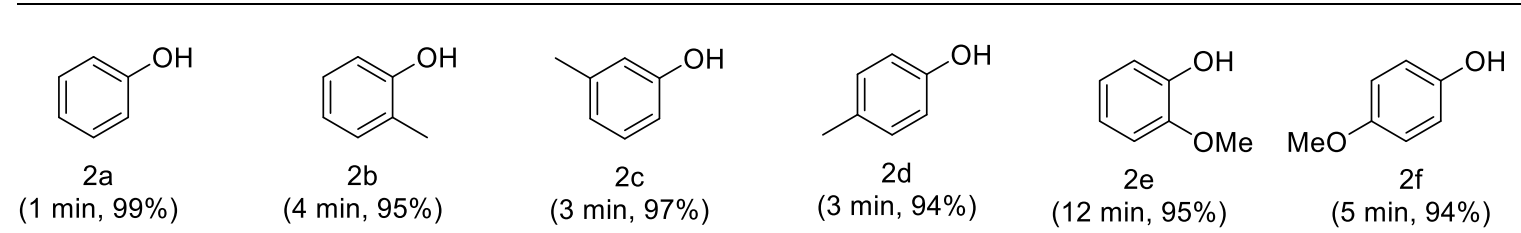

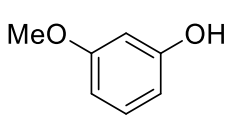

(3 $\min , 99 \%)$<smiles>Oc1ccc(I)cc1</smiles>

$2 m$

(10 min, trace)

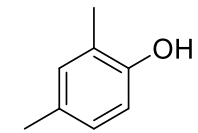

$2 \mathrm{~h}$

(10 min, 92\%)

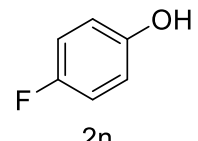

(10 min, trace)

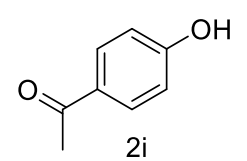

(3 min, 91\%)

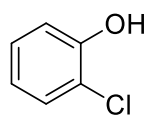

2j

(4 min, 91\%)

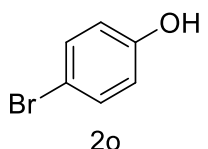

(10 min, trace)

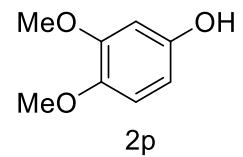

(10 min, 25\%)

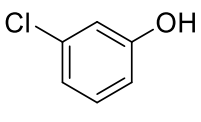

$2 \mathrm{k}$

(3 $\min , 92 \%$ )

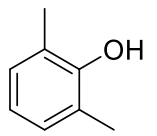

$2 q$

(10 min, trace)

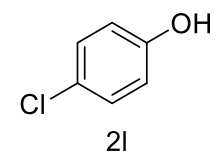

(10 min, trace)

a Reaction conditions: phenylboronic acid (1 mmol), $\mathrm{H}_{2} \mathrm{O}_{2}(1.6 \mathrm{~mL}, 53$ equiv.) at room temperature. $b$ Isolated yield. 
In order to prove our assumption, various solvents which could co-solve with water such as $\mathrm{MeOH}, \mathrm{EtOH}$, acetone were added to the hydroxylation of boronic acids. Excellent yields could then be achieved in many cases. To our delight, when EtOH was employed as the co-solvent, a quantitative yield could be obtained in one minute. In view of the environmentally friendly features of EtOH. Hence, the scope of the substrates was further tested with EtOH as co-solvent. Surprisingly, phenyl boronic acids with electron-rich and electronwithdrawing groups were converted into the corresponding product in quantitative yields, and it is worth noting that the reaction occurs very rapidly ( $1 \mathrm{~min}$ in all cased).

Table 3. Catalyst-free hydroxylation of boronic acids in EtOH ${ }^{a}$

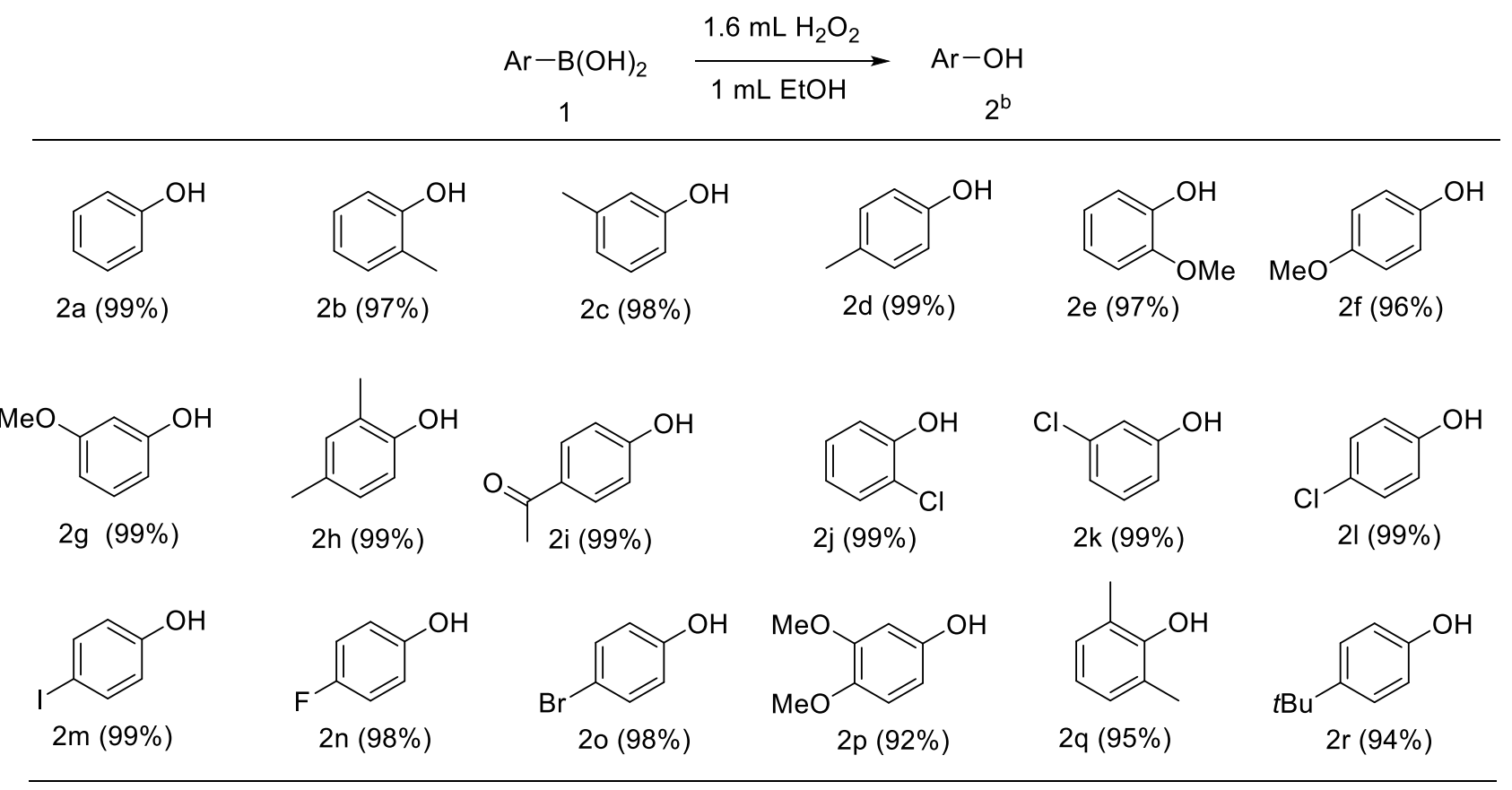

a Reaction conditions: phenylboronic acid $(1 \mathrm{mmol}), \mathrm{H}_{2} \mathrm{O}_{2}(1.6 \mathrm{~mL})$ and EtOH $(1 \mathrm{~mL})$ at room temperature, $1 \mathrm{~min}$. b Isolated yield.

Based on the literature reports, we have proposed a plausible mechanism for catalyst-free ipsohydroxylation. Firstly, phenylboronic acid reacted with hydrogen peroxide to form adduct 1 and one proton transferred to form adduct 2. Then the phenyl group migrated to oxygen to generate the adduct 3 with the removal of $\mathrm{H}^{+}$by $\mathrm{H}_{2} \mathrm{O}$. Finally, phenol formed after the hydrolysis. 


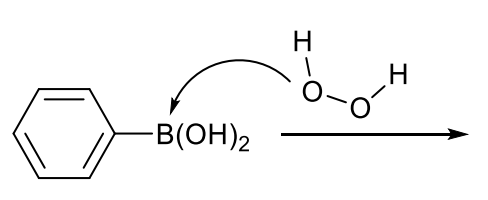

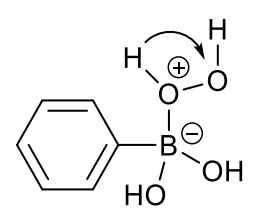

1
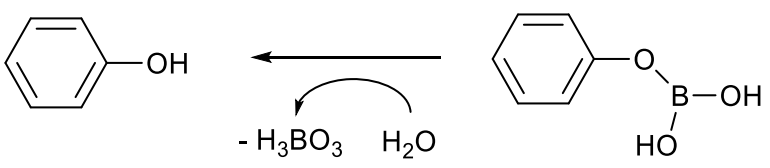

3

Scheme 1. Plausible mechanism.

\section{Conclusions}

In conclusion, we have developed a catalyst-free system for the oxidative hydroxylation of aryl boronic acids into phenols at room temperature under mild condition. The oxidative hydroxylation reactions could proceed efficiently both solvent-free and green solvent condition, affording various phenols as products with excellent yields in a very short reaction time.

\section{Experimental Section}

General. Reactions were carried out using commercially available reagents in over-dried apparatus. $\mathrm{H}_{2} \mathrm{O}_{2}$ and ethanol was commercially available and used directly. All the products are known compounds and have been reported in previous work. The ${ }^{1} \mathrm{H}$ NMR of products was corresponding with the references: $\mathbf{2 a}, \mathbf{2} \mathbf{b}, \mathbf{2} \mathbf{d}, \mathbf{2} \mathbf{f}, \mathbf{2} \mathbf{j}$, $\mathbf{2 l}, \mathbf{2 m}, 2 \mathrm{o},{ }^{8} \mathbf{2 c}, \mathbf{2 k}, \mathbf{2 n},{ }^{9} \mathbf{2 e}, \mathbf{2 g},{ }^{20} 2 \mathrm{i},{ }^{12} \mathbf{2 q},{ }^{21} \mathbf{2 r},{ }^{14} \mathbf{2 h}, \mathbf{2 p} .{ }^{22}$

\section{General procedure for the oxidation using $\mathrm{H}_{2} \mathrm{O}_{2}$}

A $25 \mathrm{ml}$ flask was charged with phenylboronic acid $(1 \mathrm{mmol})$. Then $1.6 \mathrm{~mL} \mathrm{H}_{2} \mathrm{O}_{2}$ was added under stirring. The reaction was stirred for $1 \mathrm{~min}$, then quenched by water $(10 \mathrm{ml})$. The aqueous layer was extracted with $20 \mathrm{~mL}$ ethyl acetate for three times. The combined organic layers were dried over $\mathrm{Na}_{2} \mathrm{SO}_{4}$ and concentrated under reduced pressure. The pure product was obtained without flash column chromatography and the purity was determine by TLC (thin layer chromatography).

\section{General procedure for the oxidation using $\mathrm{H}_{2} \mathrm{O}_{2}$}

A $25 \mathrm{ml}$ flask was charged with phenylboronic acid $(1 \mathrm{mmol})$. Then $1.6 \mathrm{~mL} \mathrm{H} \mathrm{O}_{2}$ and $1 \mathrm{~mL}$ EtOH were added under stirring. The reaction was stirred for $1 \mathrm{~min}$, then quenched by water $(10 \mathrm{ml})$. The aqueous layer was extracted with $20 \mathrm{~mL}$ ethyl acetate for three times. The combined organic layers were dried over $\mathrm{Na}_{2} \mathrm{SO}_{4}$ and concentrated under reduced pressure. The pure product was obtained without flash column chromatography and the purity was determine by TLC. 


\section{Acknowledgements}

The authors are grateful to the Doctor Fund of Henan University of Technology (No. 2015BS013) and the Innovative Funds Plan of Henan University of Technology (No.2020ZKCJ29).

\section{Supplementary Material}

Copies of ${ }^{1} \mathrm{H}$ NMR and mass spectra of compounds $2 a-r$ are given in the Supplementary Material file associated with this paper.

\section{References}

1. Huang, Z.; Lumb, J.-P. ACS Catalysis 2019, 9 (1), 521-555.

https://doi.org/10.1021/acscatal.8b04098

2. Wu, W.-T.; Zhang, L.; You, S.-L. Chem. Soc. Rev. 2016, 45 (6), 1570-1580. https://doi.org/10.1039/C5CS00356C

3. Sun, W.; Li, G.; Hong, L.; Wang, R. Org. Biomol. Chem. 2016, 14 (7), 2164-2176. https://doi.org/10.1039/C5OB02526E

4. Mesganaw, T.; Garg, N. K. Org. Process Res. Dev. 2013, 17 (1), 29-39. https://doi.org/10.1021/op300236f

5. Schulz, T.; Torborg, C.; Schaeffner, B.; Huang, J.; Zapf, A.; Kadyrov, R.; Boerner, A.; Beller, M. Angew. Chem. Int. Edit. 2009, 48 (5), 918-921.

https://doi.org/10.1002/anie.200804898

6. Han, J. W.; Jung, J.; Lee, Y.-M.; Nam, W.; Fukuzumi, S. Chem. Sci. 2017, 8 (10), 7119-7125. https://doi.org/10.1039/C7SC02495A

7. Cai, X.; Wang, Q.; Liu, Y.; Xie, J.; Long, Z.; Zhou, Y.; Wang, J. ACS Sustain. Eng. 2016, 4 (9), 4986-4996. https://doi.org/10.1021/acssuschemeng.6b01357

8. Karthik, M.; Suresh, P. ACS Sustain. Eng. 2019, 7 (9), 9028-9034. https://doi.org/10.1021/acssuschemeng.9b01361

9. Muhammad, M. H.; Chen, X.-L.; Liu, Y.; Shi, T.; Peng, Y.; Qu, L.; Yu, B. ACS Sustain. Eng. 2020, 8 (7), $2682-$ 2687.

https://doi.org/10.1021/acssuschemeng.9b06010

10. Kumar, I.; Sharma, R.; Kumar, R.; Kumar, R.; Sharma, U. Adv. Synth. Cat. 2018, 360, 2013-2019 https://doi.org/10.1002/adsc.201701573

11. Inamoto, K.; Nozawa, K.; Yonemoto, M.; Kondo, Y. Chem. Commun. 2011, 47, 11775-11777. https://doi.org/10.1039/c1cc14974a

12. Simon, J.; Salzbrunn, S.; Surya Prakash, G. K.; Petasis, N. A.; Olah, G. A. J. Org.Chem. 2001, 66, 633-634. https://doi.org/10.1021/jo0015873

13. Bi, S.; Thiruvengadam, P.; Wei, S.; Zhang, W.; Zhang, F.; Gao, L.; Xu, J.; Wu, D.; Chen, J.-S.; Zhang, F. J. Am. Chem. Soc. 2020, 142, 11893-11900.

https://doi.org/10.1021/jacs.0c04594

14. Yang, X.; Jiang, X.; Wang, W.; Yang, Q.; Ma, Y.; Wang, K. RSC Advances 2019, 9, 34529-34534. 
https://doi.org/10.1039/C9RA07201B

15. Paul, A.; Chatterjee, D.; Rajkamal; Halder, T.; Banerjee, S.; Yadav, S. Tetrahedron Lett. 2015, 56, $2496-2499$. https://doi.org/10.1016/j.tetlet.2015.03.107

16. Affrose, A.; Azath, I. A.; Dhakshinamoorthy, A.; Pitchumani, K. J. Mol. Cat. A: Chemical 2014, 395, $500-505$. https://doi.org/10.1016/i.molcata.2014.09.016

17. Mulakayala, N.; Ismail; Kumar, K. M.; Rapolu, R. K.; Kandagatla, B.; Rao, P.; Oruganti, S.; Pal, M. Tetrahedron Lett. 2012, 53, 6004-6007. https://doi.org/10.1016/j.tetlet.2012.08.087

18. Castro-Godoy, W. D.; Schmidt, L. C.; Argüello, J. E. Eur. J. Org. Chem. 2019, 2019, 3035-3039. https://doi.org/10.1002/ejoc.201900311

19. Kokotos, C.; Sideri, I.; Voutyritsa, E. Synlett 2017, 29, 1324-1328. https://doi.org/10.1055/s-0036-1591837

20. Kandula, V.; Nagababu, U.; Behera, M.; Yennam, S.; Chatterjee, A. J. Saudi Chem. Soc. 2019, 23, 711-717. https://doi.org/10.1016/i.jscs.2018.11.007

21. Jiang, M.; Yang, H.-J.; Li, Y.; Jia, Z.-Y.; Fu, H. Chinese Chem. Lett. 2014, 25, 715-719. https://doi.org/10.1016/j.cclet.2014.03.018

22. Kristianslund, R.; Vik, A.; Hansen, T. V. Synth. Commun. 2018, 48, 2809-2814. https://doi.org/10.1080/00397911.2018.1496263 